\title{
Annecy - 41 avenue des Romains
}

\section{Franck Gabayet}

URL : http://journals.openedition.org/adlfi/14877

ISSN : 2114-0502

Éditeur

Ministère de la culture

\section{Référence électronique}

Franck Gabayet, «Annecy - 41 avenue des Romains », ADLFI. Archéologie de la France - Informations [En ligne], Rhône-Alpes, mis en ligne le 28 mai 2015, consulté le 19 avril 2019. URL : http:// journals.openedition.org/adlfi/14877

Ce document a été généré automatiquement le 19 avril 2019

(c) Ministère de la Culture et de la Communication, CNRS 


\title{
Annecy - 41 avenue des Romains
}

\author{
Franck Gabayet
}

Code INSEE de la commune : 73010

Lien Atlas (MCC) :

http://atlas.patrimoines.culture.fr/atlas/trunk/index.php?

ap_theme=DOM_2.01.02\&ap_bbox=6.101;45.850;6.157;45.930

1 L'opération a pour origine un projet de construction d'un immeuble en lieu et place d'un hôtel et de parkings localisés sur une parcelle intégrée au zonage archéologique d'Annecy-Boutae. Le tènement est plus précisément situé dans le secteur ouest de la ville antique, principalement occupé par une nécropole. En dépit d'une surface limitée à environ $1100 \mathrm{~m}^{2}$ et de la présence des fondations de l'ancien hôtel et des parkings, neuf tranchées ont pu être implantées. Comme attendu, des tombes ont été mises au jour, mais aussi plusieurs maçonneries plus anciennes. Quelques unités stratigraphiques peuvent être rattachées à un état antérieur à la construction des murs (creusement, niveau de circulation, rubéfaction...). Hormis cette relation en chronologie relative, rien ne permet de dater les vestiges. Il est évidemment exclu d'en tenter l'analyse et de proposer un début de synthèse.

2 Tout au plus rappellera-t-on que plusieurs des sites fouillés à Boutae, dans des secteurs excentrés ont livré des occupations de la première moitié du $\mathrm{I}^{\mathrm{er}} \mathrm{s}$. av. J.-C., fréquemment associées à des systèmes fossoyés, le plus souvent remblayés au début du $\mathrm{I}^{\mathrm{er}} \mathrm{s}$. apr. J.-C. pour faire place à des constructions maçonnées (Gabayet, Gaime, 2007 ; Gabayet et al., 2011 ; Gabayet, Isnard, 2013).

L'intervention aura été l'occasion de repérer deux grands murs parallèles, Ml et M2. Dans le détail, ils présentent des caractéristiques qui restent à analyser finement. Des murs perpendiculaires sont restitués, à titre d'hypothèses, grâce à la présence de niveaux de démolition, ou de restes ténus de maçonneries mal préservées. La qualité de la construction et les matériaux mis en œuvre, en particulier pour Ml et M2, incitent à rapprocher ces constructions de certains des édifices publics, découverts par exemple durant les fouilles toutes proches des thermes du Clos-Pouget. Les rares éléments de datation fournis au 41 avenue des Romains par la céramique permettent d'avancer un 
intervalle chronologique entre le $\mathrm{I}^{\mathrm{er}}$ et le $\mathrm{III}^{\mathrm{e}} \mathrm{s}$., qui ne s'oppose pas aux résultats du ClosPouget (Bertrandy, Chevrier, Serralongue, p. 119). L'orientation des murs les mieux conservés est de $54^{\circ} \mathrm{O}$ et de $36^{\circ} \mathrm{E}$ pour les maçonneries perpendiculaires, ce qui correspond approximativement à l'une des deux grandes trames parcellaires de Boutae (Gabayet, Gaime, 2007). Les murs dégagés durant le diagnostic viennent ainsi parfaitement s'intégrer dans le tissu urbain, à la frange ouest de l'agglomération, sans doute dès le $\mathrm{I}^{\mathrm{er}} \mathrm{s}$. Quoi qu'il en soit, comme beaucoup de quartiers de Boutae, il est possible que les édifices n'aient pas survécu aux bouleversements qui affectent le bourg à la fin du II $\mathrm{e}$.

Une quarantaine de sépultures ont été repérées dans les sondages, exclusivement des inhumations.

5 Les 39 tombes restituées dans l'emprise des sondages respectent globalement l'orientation des murs, pourtant réduits à l'état de ruine et probablement masqués au moment de la constitution de l'ensemble funéraire. La plupart des fosses sont orientées autour de $50^{\circ} \mathrm{O}$ et reprennent grosso modo les orientations des tombes reconnues jusquelà au sein de la nécropole ouest. On retrouve en outre l'organisation en rangées déjà identifiée par C. Marteaux et P. Broise. Les sépultures n'ont pas livré de mobilier datant. Les rares éléments de chrono-typologie invitent à restituer des tombes en fosses couvertes, des coffrages de bois ou des coffrages de dalles...

Des analyses par le radiocarbone sont en cours, mais il est vraisemblable que la nécropole intervient tardivement dans l'histoire de Boutae, sans doute aux $\mathrm{v}^{\mathrm{e}}-\mathrm{VI}^{\mathrm{e}} \mathrm{s}$., avant l'abandon définitif de l'agglomération (Serralongue, 2002).

D'après cette hypothèse, il est vraisemblable que, selon un schéma déjà reconnu cette fois à l'est de la ville, un tènement déclassé et réduit à l'état de friches urbaines est tardivement réinvesti à des fins sépulcrales (Gabayet, Gaime, Bayen 2006).

INDEX

Index chronologique : Antiquité, haut Moyen Âge

Mots-clés : tènement, sépulture, maçonnerie

Keywords : Antiquity, Early Middle Ages

operation Opération préventive de diagnostic (OPD), 2013 - n OA : 2211348

Index géographique : Rhône-Alpes, Haute-Savoie (74), Annecy

\section{AUTEURS}

FRANCK GABAYET

Inrap 